\title{
Livro na praça: o espaço não formal contribuindo para a formação do leitor literário
}

REVISTA ELETRÔNICA CIENTÍFICA DA UERGS

Susana Cagliari

Universidade Estadual do Rio Grande do Sul (UERGS).

E-mail: cagliari.susana@gmail.com, http://lattes.cnpq.br/2 I4355442664I37 I

Veronice Camargo da Silva

Universidade Estadual do Rio Grande do Sul (UERGS).

E-mail: veronice-silva@uergs.edu.br, http://lattes.cnpq.br/6221636487022308

Submetido em: 19 ago. 2021. Aceito: 17 nov. 202। DOI: http://dx.doi.org//0.21674/2448-0479.73.240-247

\section{Resumo}

Este trabalho tem como objetivo analisar como o espaço não formal pode contribuir para a formação do leitor literário. Os instrumentos de análise foram três projetos de leitura denominados "Livro na Praça", "Árvore de Livros" e "Piquenique Literário", destinados a crianças alfabetizadas ou não. Os mesmos aconteceram em espaço não-formal, mais especificamente, no município de Canoas/RS. A metodologia utilizada neste estudo foi uma pesquisa-ação, com análise qualitativa. Nessa perspectiva, neste espaço não-formal, as crianças puderam encontrar livros diversos, fazer suas próprias escolhas, ler ou escutar histórias e, ainda, trocar livros e ideias.

Palavras-chave: Espaços não formais; literatura; leitor literário.

\section{Abstract}

Book in the square: the non-formal space contributing to the formation of the literary reader This work aims to analyze how the non formal space can contribute to the formation of the literary reader. The analysis instruments were three reading projects called "Livro na Praça", "Árvore de Livros" and Literary Picnic", aimed at children who are literate or not. The same took place in a non-formal space, more specifically, in the city of Canoas/RS. The methodology used in this study was an action research, with qualitative analysis. From this perspective, in this non-formal space, children could find different books, make their own choices, read or listen to stories, and also exchange books and ideas.

Keywords: Non-formal spaces; literature; literary reader.

\section{Resumen}

\section{Libro en la plaza: el espacio no formal que contribuye a la formación del lector literario}

Este trabajo tiene como objetivo analizar cómo el espacio no formal puede contribuir con la formación del lector literario. Los instrumentos de analisis fueron tres proyectos de lectura denominados "Libro en la plaza", "Árbol de libros" y "Picnic literario", dirigidos a niños alfabetizados o no. Dichos proyectos ocurrieron en un espacio no formal, más concretamente, en la ciudad de Canoas/RS. La metodología utilizada en este estudio fue una investigación-acción, con análisis cualitativo. Desde esta perspectiva, en este espacio no formal, los niños pudieron encontrar diferentes libros, tomar sus propias decisiones, leer o escuchar cuentos y también intercambiar libros e ideas.

Palabras clave: Espacios no formales; literatura; lector literario. 


\section{Introdução}

Sobre a leitura, Cosson (2009, p. 26) afirma que só se lê fora da escola, por prazer, se utilizar mecanismo de interpretação, que na maioria das vezes é aprendido na escola. A formação do cidadão se faz muito através da leitura. Ao ler, pode-se viajar por mundos e lugares distantes, sem sair do lugar; aprender sobre outras culturas, outros pensamentos, outras vidas. Possibilitou-se, assim, argumentar, debater e chegar a uma conclusão sobre tudo que se passa em nosso entorno.

O espaço não formal é apresentado aqui como um recurso a mais na formação do leitor. O letramento literário tem uma função diferenciada do letramento convencional que se define pelo uso social da escrita. $O$ letramento literário vai além. Uma compreensão mais efetiva sobre o que se está lendo, como diz Cosson (2009, I2): "o processo de letramento que se faz via textos literários compreende não apenas uma dimensão diferenciada do uso social da escrita, mas também, e, sobretudo, uma forma de assegurar seu efetivo domínio".

A partir dessa compreensão, fazem-se necessárias atitudes que venham ao encontro da escola para ajudar na formação de leitores literários, nas quais leitura deleite acolherá de forma livre, quem estiver disposto a ler o que tem vontade e trocar experiências sobre os textos lidos com outras pessoas sem a obrigatoriedade, que muitas vezes mutila a capacidade de apreciar um bom texto.

Em meio a todas estas informações, surge a questão: "Como um espaço não formal pode se constituir em um espaço de leitura e assim contribuir na formação de leitores literários? " Na procura pela resposta, busca-se por meio de literaturas especializadas, como em Cosson (2009), Petit (2013), Zilberman (2003), Jaccobucci (2008). Nesse sentido, o presente estudo tem por objetivo analisar como o espaço não formal pode contribuir para a formação do leitor literário.

\section{Literatura no espaço não formal de ensino}

Cosson (2009) relata sobre o ensino de literatura na sala de aula e do dever da escola formar leitores. Em relação ao ensino de literatura na escola, esse mesmo autor fala sobre o descaso que ocorre devido à falta de conhecimento dos docentes, além, é claro, da soberba de pensar que já conhecem o necessário sobre este tema. Fala também sobre a importância do estudo nestes espaços não-formalizados. Sendo assim, este estudo é de relevância, pois para ler por prazer, precisa-se dos conhecimentos adquiridos em sala de aula.

Zilberman (2003, p. 19) fala sobre o leitor literário, dizendo que ler é um privilégio quando afirma:

$O$ ato de ler se configura como uma relação privilegiada com o real, já que engloba tanto um convívio com a linguagem, como o exercício hermenêutico de interpretação dos significados ocultos que o texto enigmático suscita, a obra de fiç̧ão avulta como o modelo por excelência de leitura. Pois, sendo uma imagem simbólica do mundo que se deseja conhecer, ela nunca se dá de maneira completa e fechada.

A autora define leitura, e diz que o texto depende do leitor, pois este último deve preencher as lacunas que o autor deixou. E vai além quando relata que a ficção tem esta função, já que é um texto que necessita da interferência do leitor para adentrar no mundo do escritor.

$\mathrm{Na}$ maioria das vezes, quando se fala sobre formação do leitor, pensa-se em escola. Ao longo da vida, passa-se por momentos marcantes, convivemos em sociedade e aprendemos com os exemplos que nos são passados propositalmente ou não. Hoje com os estudos, pesquisas, noticiários sabe-se que a escola não está dando conta na formação do leitor literário. Os motivos são muitos: currículos que tem que ser cumpridos, falta de tempo para trabalhar com literatura, visão que esta matéria é mais importante do que aquela, até mesmo que o ensino da literatura é algo sem importância, ultrapassado. Cosson fala sobre as afirmações citadas acima quando diz:

Alguns acreditam que se trata de um saber desnecessário. Para esses a literatura é apenas um verniz burguês de um tempo passado, que já deveria ter sido abolido das escolas. Eles não sabem, mas pensam que não precisam aprender literatura, porque já conhecem e dominam tudo o que lhes interessa (COSSON, 2009, p. 10).

$\mathrm{E}$, assim, a literatura é deixada em segundo plano e a formação do leitor literário fica comprometida. Veem-se grandes possibilidades, talvez não tão bem aproveitadas pela sociedade, de pessoas engajadas em oferecer mudanças para auxiliar na formação leitora fora das escolas. Ou seja, há pessoas buscando lugares não tradicionais de estudo para mostrar aos indivíduos como a leitura é importante e como ela é gratificante. 
Pois, ao ler um livro, o indivíduo pode, além de encontrar conhecimento, descobrir prazer e diversão se bem direcionado. Nesta situação, não importa o local, desde que este tenha objetivos claros e bem definidos, o ensino pode ser entendido como uma educação não formal.

Assim, a educação não formal pode ser definida como a que proporciona a aprendizagem de conteúdos da escolarização formal em espaços como museus, centros de ciências, ou qualquer outro em que as atividades sejam desenvolvidas de forma bem direcionada, com um objetivo definido (VIEIRA, 2005, p. 2I).

Estes espaços não-formalizados são de grande valia na aprendizagem, pois oferecem um ambiente mais descontraído, mas que não por isso deixa de ser um local de aprendizagem, sem o pressuposto dos espaços formalizados.

Jaccobucci (2008) fala sobre os espaços não-formais, apresenta estudos feitos nestes locais cujo conhecimento transforma os sujeitos participantes, além de abordar sobre os tipos de espaços não-formais, suas funções e expectativas do uso destes ambientes na aprendizagem vivenciada.

Gerardi (2006, p.2I) diz que a literatura pode ser entendida de diversas formas, uma delas seria como instituição nacional, patrimônio cultural; bem como um sistema de obras, autores e público, como disciplina escolar confundindo-se com a história literária ou mesmo em cada texto consagrado como canônico entre outros.

Segundo Abramovich (1993, p. 17), a literatura é fundamental para as crianças, mesmo antes de se tornarem leitoras. Desde o primeiro contato, que geralmente acontece através da oralidade, a criança já faz uma ponte entre histórias e imaginação. É esta experiência que abre as portas para a compreensão do mundo.

Neste contexto, podemos dizer que a literatura infantil dá a criança um conhecimento de si mesma e do mundo em que vive, primeiro no âmbito familiar e, por fim da sociedade, pois preenche lacunas da pouca experiência existencial, que realiza por meio da linguagem simbólica (ZILBERMAN, 2003, p.27).

A literatura infantil é o primeiro passo na formação do leitor. Se a criança se encanta com os livros infantis isto pode ser alimentado conforme ela vai amadurecendo e se assim ocorrer, pode-se fomentar este encantamento durante a passagem de fases que o ser humano perpassa.

A experiência literária não só nos permite saber da vida por meio da experiência do outro, como também vivenciar essa experiência. Ou seja, a ficção feita palavra na narrativa e a palavra feita matéria na poesia são processos formativos tanto da linguagem quanto do leitor e do escritor. Uma e outra permitem que se diga o que não sabemos expressar e nos falam de maneira mais precisa o que queremos dizer ao mundo, assim como nos dizer a nós mesmos (COSSON, 2009, p. 17).

Se a literatura tem este poder de levar o leitor por outros mundos e os compreender, bem como fazer com que neste momento o leitor seja ele próprio em sua essência, o ato de ler se transforma em uma forma de oxigênio, ou seja, indispensável para a formação do cidadão.

Cosson $(2009$, p. 17$)$ vai além quando diz que a literatura deve ser vivenciada, por ser mais que um conhecimento a ser reelaborado, mas uma troca entre leitor e autor sem que o primeiro perca sua identidade.

Letramento literário é reconhecer as diversidades textuais, entendendo suas especificidades e quais os recursos que foram utilizados na elaboração do texto lido, assim como ter consciência do que se decifra e saber reformular o que foi lido, e elaborar novos saberes, não só para adquirir mais conhecimento, mas também pelo prazer que a leitura dá.

O letramento literário, conforme o concebemos, possui uma configuração especial. Pela própria condição de existência da escrita literária [...] o processo de letramento que se faz via textos literários compreende não apenas uma dimensão diferenciada do uso social da escrita, mas também, e sobretudo, uma forma de assegurar seu efetivo domínio (COSSON, 2009, p. 10).

Conseguir, através da literatura, o entendimento necessário para se viver em sociedade, saber se expressar, se empoderar do conhecimento adquirido e assim ter capacidade de participar, imaginar e vivenciar com prazer o texto que se tem em mãos, é a capacidade adquirida pelo letramento literário.

\section{Metodologia}

A metodologia utilizada neste estudo é uma pesquisa-ação (THIOLLENT, 2008) com análise qualitativa. Os objetos de análise são três projetos de leitura destinadas a crianças alfabetizadas ou não. Os mesmos 
aconteceram em espaço não-formal, mais especificamente, numa praça que localizada no bairro São Luiz, no município de Canoas/RS. Os projetos foram denominados como "Livro na Praça", "Árvore de Livros" e "Piquenique Literário".

Nessa perspectiva, neste espaço não-formal, as crianças puderam encontrar livros diversos, fazer suas próprias escolhas, ler ou escutar histórias e, ainda, trocar livros e ideias, além de fazer comentários sem a preocupação da avaliação que acontece dentro das salas.

\section{Livro na Praça}

Em um post no facebook, em um dia qualquer, uma nota: "Livro na Praça". Olhos brilhando e o enunciado: "amanhã é dia de livro na praça". Toda ideia boa deve ser partilhada e compartilhada. Na mesma hora, surgem quatro sacolinhas de TNT. Dentro de cada uma, um livro infantil. Praça, árvores, sacolas penduradas. Uma foto, mais um post no facebook e crianças do bairro correndo para buscar os livros. Em cada livro disponível, há dentro uma frase: "Este livro é seu para ler e se encantar, depois passe para outra criança, para que a mesma leia e se encante também". Sobraram crianças, faltaram livros. No dia seguinte, na página do bairro, os comentários "Meu filho queria um livro, mas não havia mais quando chegamos à praça". Assim nasceu o projeto: "Leitura na praça - Ler é descobrir um mundo de possibilidades". Um mês depois, trinta e quatro sacolas disponibilizadas na praça.

Quando um projeto é criado, gera uma expectativa, que vai oscilando entre o medo e a vontade que dê certo. Ao disponibilizar os livros na praça, se pensou que até o final do dia todos os livros seriam levados. Em menos de duas horas, não havia mais nenhum livro no local. Novas fotos, novos comentários. Agora pessoas querendo doar livros, participar de alguma maneira.

Este projeto pode ser o exemplo de que crianças e adolescentes precisam e querem ser leitores assíduos. Destaca-se que as famílias acompanharam as crianças durante os eventos e acabaram incentivando-as na leitura, pois além de ler com as crianças, ajudaram na escolha do livro. É o exemplo que falta muitas vezes em casa e/ou nas escolas, como aparece na pesquisa retratos da leitura no Brasil.

Apenas um terço dos brasileiros teve influência de alguém na formação do seu gosto pela leitura, sendo que a mãe ou responsável do sexo feminino e o professor foram as influências mais citadas. $E$ a pesquisa indica que essa influência tem impacto no fato do indivíduo ser ou não leitor, uma vez que, enquanto $83 \%$ dos não leitores não receberam a influência de ninguém, o mesmo ocorre com $55 \%$ dos leitores (FAlLA, 2016, p.I3I).

Exemplos positivos influenciam e fazem a diferença. Se faltar exemplo de leitores nas escolas ou em casa o entorno pode suprir esta falta com projetos que convidem a comunidade toda a participar.

Novas ideias, próximo passo: "piquenique literário"; cardápio: livros infantis, infantojuvenis, romances, clássicos, gibis etc. Encontro com as crianças que estão com as sacolas, troca de livros, troca de experiências sobre as leituras realizadas, contação de histórias e tudo de bom que os livros possam proporcionar a cada um que tenha vontade de participar.

Novas datas, novos livros, novas experiências e assim interagir, doar, ler, contar, ensinar aprender e o mais importante: incentivar a leitura, pelo simples prazer em ler. Desse modo, fomentar a formação de leitores literários.

\section{Árvore de Livros}

Uma praça, muitas árvores, um convite: sentar-se nas suas sombras e viajar através de um bom livro, através de um belo texto de uma boa poesia; contar histórias para crianças fomenta o gosto pela leitura. As histórias fazem brotar sentimentos diversos, segundo Abramovich (1993, p.17) elas, sentem, ouvem e enxergam com os olhos da imaginação.

Parece que árvore e livros combinam. Combinam tanto que ao pendurar, sacolinhas com livros, nas árvores da praça, a mesma praça de todos os dias, ficou mais encantadora. Parecia estar florida e proporcionando muita alegria às crianças que por ali passavam. Uma combinação perfeita, sem dúvida é crianças, árvores e livros. Pensando assim, surge a ideia de fazer as árvores florescerem. Flores? Não! Livros.

A praça do bairro amanheceu florida de livros. Parecia estranho, mas a criançada amou a experiência e não questionou um minuto que árvores não dão livros e que ali havia a floração de livros. No facebook, foi postado: "nossa praça amanheceu florida, as árvores estão repletas de livros para vocês, crianças, colherem". 
Essa é a magia que encanta as crianças. Para elas tudo é possível, tudo é imaginável. Esta mágica que se tem que tentar manter por toda a vida. Nesta fase, formar leitores é muito mais fácil. Manter este encantamento é o que o projeto visa a conquistar.

Ao ler para uma criança e ver o brilho nos olhos, além da curiosidade estampada em seus rostos, há a esperança de levar este brilho para todos que se encontram neste percurso. Para Cosson (2009), a aprendizagem por meio da literatura está relacionada aos saberes e às habilidades proporcionadas aos usuários pela prática da leitura literária.

Petit (20I3) explica que não se prende alguém em uma cabana para ler e assim formar um leitor, mas que temos que oportunizar a eles, que criem seus próprios caminhos, suas próprias suposições. Nesse sentido, a praça é um lugar que possibilita a leitura deleite, favorecendo a imaginação e a colaboração com a liberdade de participar, ler, ouvir, levar, contar ou apenas apreciar o momento.

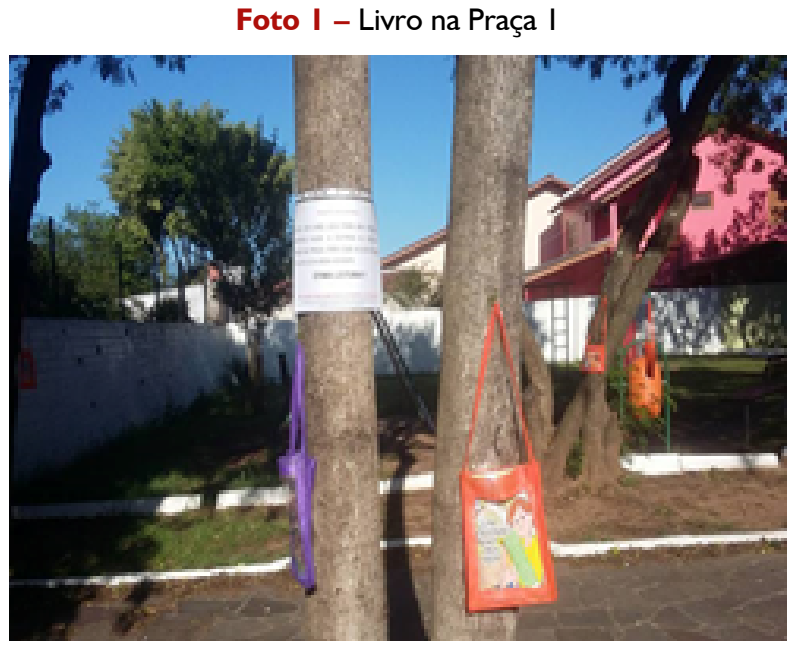

Fonte: Autoras

Foto 2 - Livro na Praça I

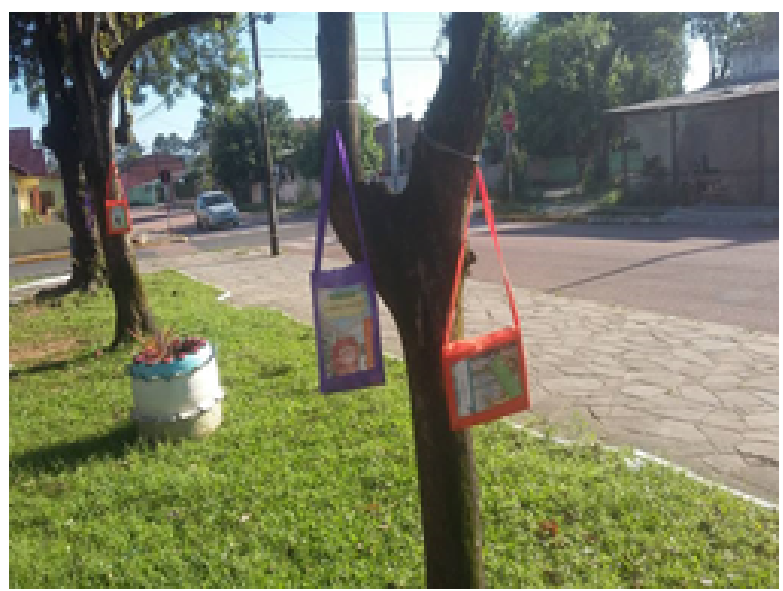

Fonte: Autoras

A praça amanheceu florida. Florida, sim, de livros, de histórias para ler e ouvir, pois é através destas histórias que se compreende e interpreta-se o mundo, como diz Abramovich (1993, p. I7): "ler histórias para as crianças, sempre, sempre".

\section{Piquenique Literário}

O piquenique literário nasceu da vontade imensa de conhecer os leitores e compartilhar experiências. De querer saber se o livro encantou, ou não, as crianças que participaram desse evento porque nele a ação acontece. De acordo com Thiollent (2008, p. 14), a pesquisa-ação ocorre na troca, na busca onde os atores se envolvem e fazem parte da experiência a fim de atingir os objetivos previstos. 
Novos desejos emergiram ao compartilhar com as crianças esses momentos: com quem convivem? As pessoas de sua convivência são leitores? Que tipos de leitores são? Por que também não possibilitar este encantamento a essas pessoas?

Os comentários sobre as ações realizadas pelo evento Piquenique Literário que foram postados pelos participantes, na página do facebook, criada pela associação de bairro, só reforçaram a vontade imensa de conhecer o público envolvido. Quando as pessoas que seguiam a página, começaram a questionar se podiam doar livros e, também, se os mesmos poderiam ser de outros gêneros, além dos infantis, cresce a possibilidade de formar e incentivar novos leitores.

Apresenta-se, a seguir, a transcrição de um diálogo que reforça a ideia do projeto.

- Por que piquenique? Vai ter comida?

- Vai ter degustação.

- Degustação? O que de bom vai ter?

- Diversos livros infantis, infantojuvenis, romances, aventuras, suspense entre outros. Quer cardápio melhor que esse?

- Hum legal, gostei!

Muitas vezes, as pessoas esperam respostas convincentes para poderem se jogar em novas experiências. Para conquistar novos leitores, é preciso usar a criatividade. Mostrar-lhes que há caminhos diferentes; que o livro, muitas vezes, proporciona prazeres inimagináveis. Que só sabe e sente isso quem se aventurar a abrir um livro e ler com sua mente e seu coração abertos. Buscar o entendimento, dialogar com o autor ou, até mesmo, questioná-lo são caminhos para se encantar e descobrir um mundo de possibilidades que os livros oferecem. Esta capacidade vai ao encontro dos sentimentos, dos conhecimentos prévios e das fantasias do próprio leitor. Para Petit:

Não nos esqueçamos, o leitor não consome passivamente um texto, ele se apropria dele, o interpreta, deturpa seu sentido, desliza sua fantasia, seu desejo, suas angústias entre as linhas e as mescla com o autor. É aí, em toda essa atividade fantasmática, neste trabalho psíquico, que o leitor se constrói (PETIT, 2013. p. 27).

O leitor interage com o autor e, assim, constrói suas próprias conclusões e sentidos, que podem ou não ser como as do autor. Esta interação pode dar ao leitor autonomia para permanecer ou mudar a forma de pensar e entender o mundo.

Foto 3 - Piquenique Literário

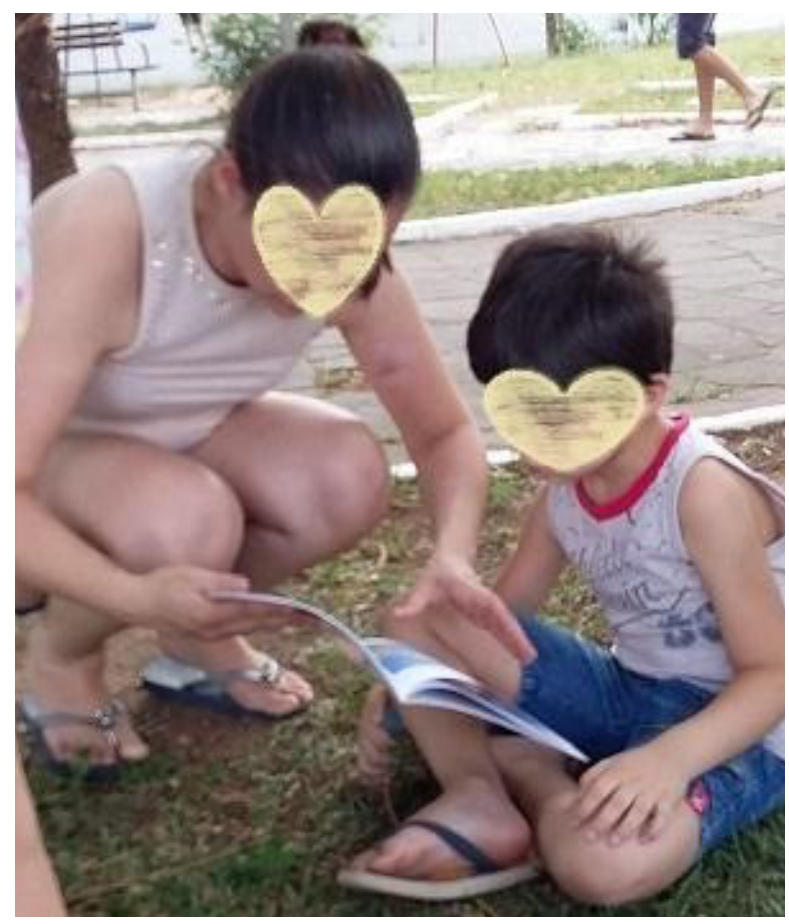

Fonte: Autoras 
Foto 4 - Piquenique Literário

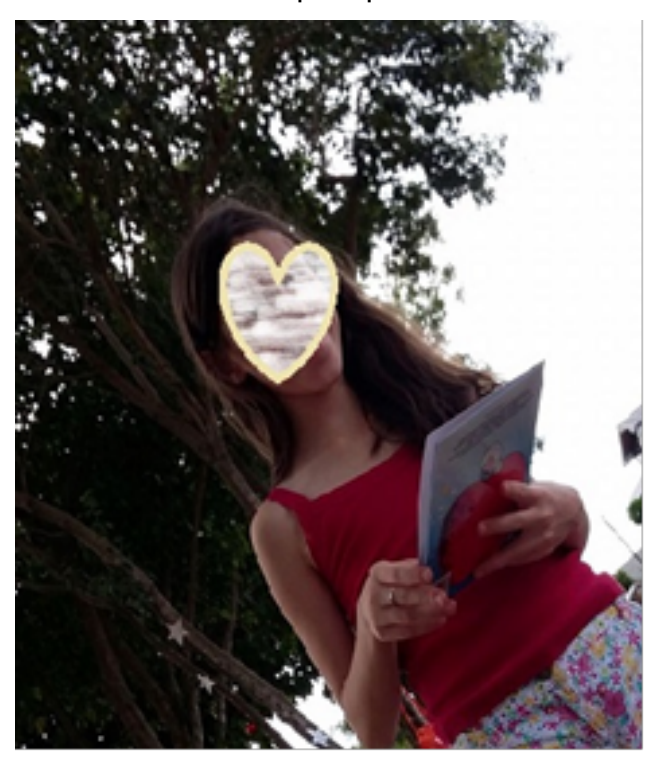

Fonte: Autoras

$\mathrm{Na}$ foto 3, a mãe lê o livro que o filho escolheu. $\mathrm{O}$ interesse dele pela história foi comovente.

Além deste livro, o menino escolheu mais dois livros que a mãe também leu. Na hora de ir embora, pediu para levar mais dois livros para casa.

$\mathrm{Na}$ foto 4, a menina escolhendo o próximo livro a ser lido. Esta menina já levou dez livros, leu todos e partilhou com primos e amigos. É uma incentivadora assídua do projeto. Convida seus amigos e todas as crianças que aparecem na praça para participar do projeto, além de indicar livros.

Durante o piquenique literário, a atenção voltou-se para uma família, composta por pai e dois filhos, que passavam pela praça e pararam para observar o que estava ocorrendo. Ao saber que os livros expostos estavam disponíveis para leitura, os três começaram a participar olhando e comentando sobre alguns títulos. Depois que os participantes escolheram seu livro e se sentaram no banco da praça, folhearam com interesse e começaram a leitura. Em seguida, perguntaram como podiam levar os livros para casa. Foram informados de que a única condição para participar do projeto era que, após a leitura, deveriam passar o livro a diante para que outra pessoa também tivesse a oportunidade de lê-lo. No final, a certeza de que ler faz um bem enorme tanto para quem oportuniza a leitura como para quem lê.

\section{Considerações finais}

O entendimento sobre a relevância de espaços não formais, utilizados como espaço de aprendizagem, pode e deve contribuir com as instituições formais como a escola. Este projeto mostrou que estes espaços não vão contra as instituições escolares, mas tornam-se lugares de aprendizagem de crianças e de adolescentes. Vê-se que a leitura, fora da escola é de importância fundamental na formação do cidadão, já que as crianças que participam do projeto, segundo alguns depoimentos, demonstraram mais interesse pelos estudos e pela leitura em si. Constatou-se também que tempo e espaço igualmente definem o que é literário ou não.

Já sobre o letramento literário, nota-se que leitores literários passam a ter mais conhecimento de mundo e, com isso, tornam-se cidadãos que entendem melhor o mundo e conseguem se posicionar de uma forma mais coerente dentro da sociedade em que estão inseridos. O mais relevante foi verificar e comprovar que a leitura deleite traz ao leitor, um aprendizado real. Para as pesquisadoras, a aprendizagem durante a realização do projeto trouxe a certeza que muito foi apreendido; contudo, o caminho a percorrer ainda é grande, além da convicção de que as possibilidades encontradas em um espaço não formal são inúmeras.

Dessa forma, este estudo buscou subsídios para seguir com estes projetos por tempo indeterminado. Foi definido que o projeto acontecerá enquanto houver interesse de crianças, adolescentes ou adultos pela leitura deleite, uma vez que é através dessa leitura, que todos são capazes de ir além da imaginação e, ainda, terem o entendimento necessário para a compreensão do mundo em que vivem. 
Por fim, destaca-se que os projetos incentivaram o público-alvo a buscar na literatura um momento de lazer e descobertas. Logo, esta clareza só é possibilitada através da troca que ocorre entre autores e leitores, bem como na troca de experiências vivenciadas nos livros, com outros leitores.

\section{Referências}

ABRAMOVICH, F. Literatura infantil: gostosuras e bobices. São Paulo: Scipione, 1993. 173p.

COSSON, R. Letramento literário: teoria e prática. São Paulo: Editora Contexto, 2009.

FAILA, Z. (org.). Retrato da leitura no brasil 4. Rio de Janeiro: Sextante, 2016. Disponível em: http://prolivro.org.br/ home/images/relatorios_boletins/3_ed_pesquisa_retratos_leitura_IPL.pdf. Acesso em: 23 jan. 2020.

GERALDI, J. W. (Org.). O texto na sala de aula. 4a . ed. São Paulo: Ática, 2006. I36 p.

JACOBUCCI, D. F. C. Contribuições dos espaços não-formais de educação para a formação da cultura científica. EM EXTENSÃO, V. 7, Uberlândia, Proex EDUFU, 2008. Disponível em: http://www.seer.ufu.br/index.php/ revextensao/article/view/20390. Acesso em: 05 dez. 2019.

PETIT, M. Leituras: do espaço íntimo ao espaço público. Iª. ed. São Paulo: Editora 34, 2013.

THIOLLENT, M. Metodologia da pesquisa-ação. 16ª. ed. São Paulo: Cortez, 2008. 132 p.

VIEIRA, V.; BIANCONI, M. L.; DIAS, M. Espaços não-formais de ensino e o currículo de ciências. Ciência e Cultura, São Paulo, n. 4, Oct./Dec. 2005. Dispónivel em: http://cienciaecultura.bvs.br/scielo.php?script=sci_arttext\&pi$\mathrm{d}=$ S0009-672520050004000 I 4 \&lng=en\&nrm=iso\&tlng=pt. Acesso em: 17 fev. 2019.

ZILBERMAN, R. A leitura na escola. In: Leitura em crise na escola: as alternativas do professor. $9^{a}$. ed. Porto Alegre: Mercado Aberto, 2003. 